1. MBBS, DCH,

FCPS (Pediatric Medicine)

Associate Professor Pediatric

Medicine

DG Khan Medical College \&

Hospital, DG Khan.

2. MBBS, FCPS (Pediatric Medicine)

Assistant Professor Pediatric

Medicine

DG Khan Medical College \&

Hospital, DG Khan

3. MBBS, FCPS (Pediatric Medicine) Senior Registrar Pediatric Medicine DG Khan Medical College \& Hospital, DG Khan.

4. MBBS, FCPS (Peads Medicine)

Assistant Professor Pediatric

Medicine

Nishtar Medical University Hospital Multan.

5. MBBS, FCPS (Pediatric Medicine)

Assistant Professor Pediatric

Medicine

DG Khan Medical College \&

Hospital, DG Khan.

6. MBBS, FCPS (Pediatric Medicine)

Senior Registrar Pediatric Medicine

DG Khan Medical College \&

Hospital, DG Khan.

Correspondence Address:

Dr. Shakeel Ahmed

Associate Professor Pediatric Medicine

DG Khan Medical College \& Hospital,

DG Khan.

dr_leghari190@hotmail.com

Article received on:

09/10/2020

Accepted for publication:

$12 / 12 / 2020$

\section{Common complications and outcome of prematurity at Dera Ghazi Khan Medical College and Hospital.}

\begin{abstract}
Shakeel Ahmed', Ayaz Ali ${ }^{2}$, Iram Jabeen ${ }^{3}$, Nusrat Hussain ${ }^{4}$, Asma Akbar ${ }^{5}$, Irfan Kareem ${ }^{6}$
ABSTRACT... Objective: To evaluate the common complications of prematurity with final outcome. Study Design: Prospective Observational Cohort study. Setting: Neonatal Unit at Dera Ghazi Khan Medical College (DGKMC) \& Hospital. Period: 8 Jan 2020 to 29 Feb 2020. Material \& Methods: Study population comprised of 100 neonates of gestational ages between 28-36 weeks, admitted for different reasons. Common complications of prematurity like Hypoxic ischemic Encephalopathy (HIE), Sepsis, Respiratory Distress Syndrome (RDS) and Necrotizing Enterocolitis (NEC) were noted and patients were followed for final outcome in terms of survived, Expired and LAMA. Results: Among the total 100 premature newborns, 59 $(59.0 \%)$ were males and 41 (41.0\%) females. There were $57(57.0 \%)$ premature newborns who were delivered through spontaneous vaginal deliveries (SVDs) while $43(43.0 \%)$ through lower segment cesarean section (LSCS). HIE was the most common complication, observed in 31 (31.0\%) babies. Sepsis was the second most common complication observed in $18(18.0 \%)$ cases. In terms of outcome, 72 (72.0\%) survived, $23(23.0 \%)$ expired and $5(5.0 \%)$ were left against medical advice (LAMA). Conclusion: Hypoxic ischemic encephalopathy was the most common complication observed either presented alone or in association with other observed complications. The most common cause of mortality in the observed population was hypoxic ischemic encephalopathy.

Key words

Complication, Gestational Age, Outcome, Prematurity.

Article Citation: Ahmed S, Ali A, Jabeen I, Hussain N, Akbar A, Karim I. Common complications and outcome of prematurity at Dera Ghazi Khan Medical College and Hospital. Professional Med J 2021; 28(9):1331-1335. https://doi.org/10.29309/TPMJ/2021.28.09.6262
\end{abstract}

\section{INTRODUCTION}

Prematurity is among the leading neonatal problems causing multiple complications with variable outcome depending upon available facilities and timely anticipated management at various centers. ${ }^{1}$ Common complications of prematurity are Hypothermia, Hypoglycemia, RDS (Respiratory Distress Syndrome), NEC (Necrotizing enterocolifis), Sepsis, HIE (Hypoxic ischemic encephalopathy, Anemia of prematurity, Apnea of prematurity, Osteopenia of prematurity and many more. ${ }^{2}$ However, time of presentation of these complications usually vary with the exception of HIE and RDS which present early. ${ }^{3}$

Multi-disciplinary approaches with enhanced modalities and timely controlled management have turned out the tables for premature neonates worldwide, resulting in greater survival and limited morbidities. ${ }^{4,5}$ In Pakistan, however, condition is still worrisome owing to limited medical facilities, lack of required resources, trained staff and necessary medical equipment. Lack of needed antenatal care, poorly planned deliveries of high risk pregnancies and failure to provide anticipated neonatal care to premature neonates are among the leading factors causing high neonatal morbidity and mortality. 6,7

DGKMC \& Hospital, being only tertiary care hospital at D.G Khan receive multiple referrals from peripheral areas with premature neonates along with complications. In this study, we tried to evaluate the prevalence of common complications and their outcome in admitted premature neonates. 


\section{MATERIAL \& METHODS}

This was a prospective observational cohort study conducted in the indoor settings of neonatal unit DGKMC \& Hospital. Premature neonates $(n=100)$ with gestational ages between 28 to 32 weeks, admitted between dated. 8-01-2020 to 29-02-2020 was enrolled for this study purpose. Congenital heart disease and pneumonia were excluded and diagnosis was further confirmed by X-ray chest. Approval from institute's ethical committee was taken for this study. Informed consent was sought from parents/guardians of the study participants.

Gestational age was assessed through Standard Ballard Scoring. Admitted neonates were observed for complications like. HIE, RDS, NEC and/or Sepsis. These neonates were also followed for the final outcome that is survived /Expired/ LAMA. Our diagnosis of each complication was mainly dependent upon history and clinical examination with minimum aid from investigations including baseline $\mathrm{CBC}$ and X-rays due to limited resources. HIE was diagnosed in neonates presenting immediately after birth with grunting, cyanosis, respiratory distress or fits from birth till 48 Hours along with history of delayed cry and maternal PV bleeding/PROM/ Obstructed or Prolonged labor. For Sepsis, we labeled neonates admitted from $3^{\text {rd }}$ day of life till 28 days with fever, lethargy, reluctance to feed, fits or difficulty in breathing. We also did CBC and considered leukocytosis and Thrombocytopenia as significant markers of Sepsis. For NEC, we labeled neonates presented with abdominal distension, vomiting, and lethargy after initiation feed, X-ray Abdomen (erect posture) and CBC was done as supportive evidence. Thrombocytopenia on $\mathrm{CBC}$ and unchanged gut loop patterns on abdominal X-ray were taken significant. For RDS, premature neonates with progressive respiratory distress developing after 24 hours of birth were enrolled. All neonates enrolled were observed for single or multiple complications and followed for final outcome in the form of survived/Expired or LAMA.

SPSS version 26.0 was used for the statistical analysis. A predesigned proforma was used for data collection. Gestational age and weight of babies were represented as mean and standard deviation. Study variables like gender, mode of delivery of the babies, complications and outcomes were represented as frequency and percentages.

\section{RESULTS}

Gestational age varied from 28-36 weeks with maximum population (37\%) admitted at $32 \pm 2$ Weeks. Mean birth weight was noted to be 2124 +217 grams. Among the total, $57 \%$ were SVDs while $43 \%$ were delivered through C-Section. Studied population comprised of $59 \%$ Males and $41 \%$ Females.

\begin{tabular}{|c|c|c|}
\hline \multicolumn{2}{|c|}{ Characteristics } & Number (\%) \\
\hline \multirow{2}{*}{ Gender } & Male & 59 (59.0\%) \\
\hline & Female & $41(41.0 \%)$ \\
\hline \multirow{2}{*}{$\begin{array}{l}\text { Gestational } \\
\text { Age (weeks) }\end{array}$} & 28 to 32 & $42(42.0 \%)$ \\
\hline & $>32$ to 36 & $58(58.0 \%)$ \\
\hline \multirow{2}{*}{$\begin{array}{l}\text { Mode of } \\
\text { Delivery }\end{array}$} & $\begin{array}{c}\text { Spontaneous Vaginal } \\
\text { Delivery }\end{array}$ & 57 (57.0\%) \\
\hline & Cesarean Section & $43(43.0 \%)$ \\
\hline \multirow{4}{*}{ Birth Weight } & $\begin{array}{l}\text { Extremely low birth } \\
\text { weight }(<1 \mathrm{~kg})\end{array}$ & $4(4.0 \%)$ \\
\hline & $\begin{array}{c}\text { Very low birth weight } \\
(1-1.5 \mathrm{~kg})\end{array}$ & $34(34.0 \%)$ \\
\hline & $\begin{array}{c}\text { Low birth weight (1.5- } \\
2.5 \mathrm{~kg})\end{array}$ & 49 (49.0\%) \\
\hline & $\begin{array}{c}\text { Normal birth weight } \\
\quad(>2.5 \mathrm{~kg})\end{array}$ & $13(13.0 \%)$ \\
\hline
\end{tabular}

Table-I. Characteristics of premature babies $(n=100)$.

HIE was the most common complication, observed in 31 (31.0\%) babies. Out of these 31, $11(11.0 \%)$ were associated with sepsis while 6 (6.0\%) also had RDS. Sepsis was the $2^{\text {nd }}$ most common complication observed in 18 (18.0\%) cases. Table-II highlights complications noted among study participants.

\begin{tabular}{|l|c|}
\hline \multicolumn{1}{|c|}{ Complications } & Number (\%) \\
\hline Hypoxic Ischemic Encephalopathy & $31(31.0 \%)$ \\
\hline Sepsis & $18(18.0 \%)$ \\
\hline Respiratory Distress Syndrome & $8(8.0 \%)$ \\
\hline Necrotizing Enterocolitis & $6(6.0 \%)$ \\
\hline \begin{tabular}{l} 
Others \\
\multicolumn{2}{|c|}{ Table-II. Frequency of Complications among } \\
Premature Babies (n=100).
\end{tabular} \\
\hline \multicolumn{2}{|c|}{}
\end{tabular}


In terms of outcome, out of the total of 100 enrolled cases, 72 (72.0\%) survived, 23 (23.0\%) expired and $5(5.0 \%)$ were LAMA. Among the expiries, HIE caused maximum number of mortalities i.e. (11 patients). HIE with Sepsis was the cause of death in 5 patients, 2 patients died each from HIE along with RDS, Sepsis along with RDS, and Sepsis with NEC. One patient died due to Sepsis. LAMA patients could not be followed for the final outcome.

\begin{tabular}{|l|c|}
\hline \multicolumn{1}{|c|}{ Outcome } & Number (\%) \\
\hline Discharged & $72(72.0 \%)$ \\
\hline Expired & $23(23.0 \%)$ \\
\hline Left Against Medical Advice (LAMA) & $5(5.0 \%)$ \\
\hline \multicolumn{2}{|c|}{ Table-III. Outcome in Premature Babies. } \\
\hline
\end{tabular}

\section{DISCUSSION}

Prematurity is an important reason behind neonatal mortality all around the globe. Better understanding of the morbidity patterns among premature newborns can help clinicians improving the survival rates and decreasing the neonatal death rates. ${ }^{8,9}$

In the present study, $59 \%$ of the premature babies were male. This male predominance among premature newborns have already been recorded by other local and international researchers as well. ${ }^{10,11}$ The exact phenomenon about this male predominance among premature newborns is still unknown but it could be due to multifactorial involvement of different hormonal, genetic and immunological differences. ${ }^{10} \mathrm{We}$ also noted mode of delivery as lower segment cesarean section (LSCS) in $43 \%$ cases. This high proportion of can be elaborated as majority of these pregnancies were having high-risk pregnancies along with comorbidities which need early cesarean section.

We noted $58.0 \%$ of the cases to have gestational age above 32 weeks. Khan HS et al from Rawalpindi analyzing 199 preterm babies also noted $54.8 \%$ of the premature newborns to have gestational age above 32 weeks. ${ }^{12}$ Chowdareddy et al also reported similar findings. ${ }^{13}$ We found birth weight of the premature newborns to be extremely low birth weight $(<1 \mathrm{~kg})$ in $4.0 \%$ cases, very low birth weight $(1-1.5 \mathrm{~kg})$ in $34.0 \%$, low birth weight
$(1.5-2.5 \mathrm{~kg})$ in $49.0 \%$ while $13 \%$ newborns were having normal birth weight $(>2.5 \mathrm{~kg})$. Khan HS et al found premature babies with VLBW as $32.7 \%$ and $46.7 \%$ were of LBW. ${ }^{12}$ Similar percentage of birth weight was reported in another study with $26.4 \%$ VLBW and $51.8 \%$ LBW preterm babies. ${ }^{14}$

In this study, mortality was noted to be $23 \%$ among premature newborns. Khan $\mathrm{M}$ et $\mathrm{al}^{14}$ reported mortality among premature newborns to be $14 \%$ while Khan $\mathrm{HS}$ et al ${ }^{12}$ found it to be $16 \%$. Chowdareddy et al recorded it to be $8.62 \% .{ }^{13}$ All this data shows difference in mortality rates among different healthcare settings which could be attributed to difference in healthcare facilities available.

In the present study, HIE was the most common complication recorded among $31.0 \%$ premature newborns, followed by sepsis $18.0 \%$ and RDS $8.0 \%$. These findings are different from what was found by Khan HS et al who noted sepsis to be the commonest complication among premature newborns. ${ }^{12}$ We found NEC to affect $6 \%$ of premature newborns. Shah $\mathrm{SH}$ et al ${ }^{15}$ in another local study reported $14.3 \%$ of the premature newborns with NEC while Khan $\mathrm{HS}^{12}$ observed NEC to affect $15.5 \%$ of the premature newborns. A study from Nigeria noted RDS to affect $68.8 \%$ premature newborns while sepsis (39\%) was the other commonest complication. ${ }^{16}$ All this data shows difference in patterns of complications noted among premature newborns. This could also be indication different etiologies behind these complications which we were unable to address in the present study and this was one of the limitations of this study. Early screening of fetal, maternal and social risk factors leading to pre-term birth must be initiated in order to reduce its incidence of premature births. Reducing preterm birth can result in better health outcomes such as improvement of overall neonatal health and significantly reduced neonatal mortality in future.

\section{CONCLUSION}

Hypoxic ischemic encephalopathy was the most common complication observed either presented alone or in association with other observed 
complications. The most common cause of mortality in the observed population was hypoxic ischemic encephalopathy.

Copyright@ 12 Dec, 2020.

\section{REFERENCES}

1. Mekuriyaw AM, Mihret MS, Yismaw AE. Determinants of preterm birth among women who gave birth in Amhara Region Referral Hospitals, Northern Ethiopia, 2018: Institutional based case control study. Int J Pediatr. 2020; 2020:1854073.

2. Suman V, Luther EE. Preterm labor. 2020 Nov 21. In: Stat Pearls [Internet]. Treasure Island (FL): Stat Pearls Publishing; 2020. PMID: 30725624.

3. Jenster M, Bonifacio SL, Ruel T, et al. Maternal or neonatal infection: Association with neonatal encephalopathy outcomes. Pediatr Res. 2014; 76(1):93-99.

4. Glass HC, Costarino AT, Stayer SA, Brett CM, Cladis F, Davis PJ. Outcomes for extremely premature infants. Anesth Analg. 2015; 120(6):1337-1351.

5. Pierrat V, Marchand-Martin L, Arnaud C, Kaminski M, Resche-Rigon M, Lebeaux C, etal. Neurodevelopmental outcome at 2 years for preterm children born at 22 to 34 weeks' gestation in France in 2011: EPIPAGE-2 cohort study. BMJ. 2017; 358:j3448.

6. Hanif A, Ashraf T, Waheed K, Sajid MR, Guler N, Pervaiz MK. Prevalence of preterm birth in Pakistan: A systemic review and meta-analysis. Ann King Edw Med Univ. 2017; 23(2):229-235.

7. Khan A, Kinney MV, Hazir T, Hafeez A, Wall SN, Ali N, et al. Newborn survival in Pakistan: $A$ decade of change and future implications. Health policy plan. 2012; 27(3):72-87.

8. Goldenberg RL, Culhane JF, lams JD, Romero R. Epidemiology and causes of preterm birth. Lancet 2008; 371(9606):75-84.
9. Blencowe H, Cousens S, Oestergaard M, Chou D, Moller $A B, N a r w a l ~ R$ et al. National, regional and worldwide estimates of preterm birth rates in the year 2010 with time trends since 1990 for selected countries: A systematic analysis and implications. Lancet. 2012; 379(9832):2162-2172.

10. O'Driscoll DN, McGovern M, Greene CM, Molloy EJ. Gender disparities in preterm neonatal outcomes. Acta Paediatr. 2018; 107(9):1494-1499.

11. Rehman AU, Qureshi AM, Najeeb S, Siddiqui TS, Idris $M$, Ahmad T. An audit of morbidity and mortality of hospitalized neonates in neonatal care unit of a tertiary care hospital in Abbottabad. J Ayub Med Coll Abbottabad. 2011;23(3):23-5

12. Khan HS, Khalil S, Akhtar P. Morbidity and mortality pattern of pre-terms. J Islamabad Med Dent College 2016; 5(1):77-80.

13. Chowdareddy N, Kumar AY, Thomas A, Deepthi UK, Ravichander. Mortality pattern of preterm infants and etiological factors of preterm births in rural tertiary care center: A retrospective study. Int J Scientific Res Publications. 2014; 4(3):2250-3153.

14. Khan M., Maheshwari $P$, Shamim $H$, Ahmed S, Ali $\mathrm{S}$. Morbidity pattern of sick hospitalized preterm infants in Karachi, Pakistan. J Pak Med Assoc. 2012; 62(4):386-8.

15. Shah SH, Saleem M, Mehmood T, Ahmed T. Frequency and outcome of necrotizing enterocolitis in preterm neonates. JAyub Med Coll Abbottabad. 2015; 27(1):857.

16. Kunle-Olowu $O$, Peterside $O$, Adeyemi O. Prevalence and outcome of preterm admissions at the neonatal unit of a tertiary health centre in Southern Nigeria. Open J Pediatr. 2014; 4(1):67-75. 


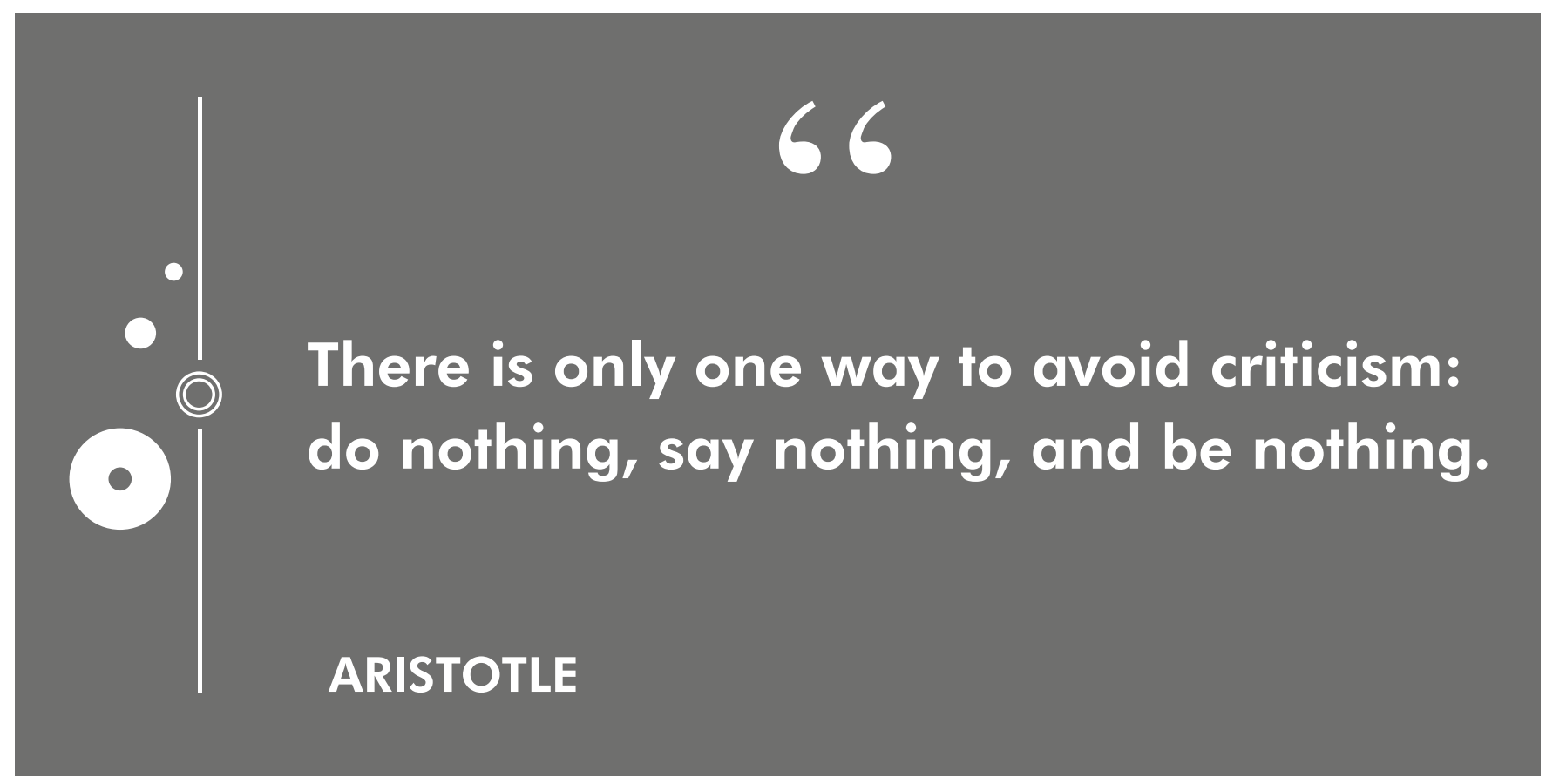

\begin{tabular}{|c|l|l|l|}
\hline \multicolumn{3}{|c|}{ AUTHORSHIP AND CONTRIBUTION DECLARATION } \\
\hline Sr. \# & \multicolumn{1}{|c|}{ Author(s) Full Name } & \multicolumn{1}{|c|}{ Contribution to the paper } & Author(s) Signature \\
\hline 1 & Shakeel Ahmed & $\begin{array}{l}\text { Study idea, Design, } \\
\text { Supervision. } \\
\text { Literature review, Proof } \\
\text { reading. } \\
\text { Discussion, Drafting. }\end{array}$ \\
\hline 3 & Ayaz Ali & Iram Jabeen & $\begin{array}{l}\text { Data analysis, Data } \\
\text { interpretation. } \\
\text { Discussion, Literature } \\
\text { Review. } \\
\text { Data collection, Introduction. }\end{array}$ \\
\hline 5 & Asma Akbar & Irfan Kareem & Asma \\
\hline
\end{tabular}

